九州大学学術情報リポジトリ

Kyushu University Institutional Repository

\title{
Evaluation of Reused Water Effect on Irrigation Water Quality of Low-Lying Paddy Area
}

Jayadi, Rachmad

Laboratory of Irrigation and Water Utilization Engineering, Faculty of Agriculture, Kyushu University

Fukuda, Tetsuro

Laboratory of Irrigation and Water Utilization Engineering, Faculty of Agriculture, Kyushu University

Nakano, Yoshisuke

Laboratory of Irrigation and Water Utilization Engineering, Faculty of Agriculture, Kyushu University

Kuroda, Masaharu

Laboratory of Irrigation and Water Utilization Engineering, Faculty of Agriculture, Kyushu University

https://doi.org/10.5109/24321

出版情報：九州大学大学院農学研究院紀要. 44 (1/2)，pp. 199-211，1999-11. Kyushu University バージョン：

権利関係 : 
J. Fac. Agr., Kyushu Cniv., 44 (1·2), 199-211 (1999)

\title{
Evaluation of Reused Water Effect on Irrigation Water Quality of Low-lying Paddy Area
}

\author{
Rachmad Jayadi, Tetsuro Fukuda, Yoshisuke Nakano and Masaharu Kuroda
}

Laboratory of Irrigation and Water Utilization Engineering, Faculty of Agriculture, Kyushu University, Hakozaki, Higashi-kı, Fukuoka 812-8581, JAPAN

(Receined July 30, 1999 and accepted August 24, 1999)

\begin{abstract}
This paper presents results of a case study on reused water effect on the irrigation water quality in a low-lying paddy area with creek networks. The study was conducted through the procedure of observations on the increment values of water quality indices $(\triangle \mathrm{COD}, \triangle \mathrm{EC}$ and $\Delta \mathrm{T}-\mathrm{N})$ at arbitrary points in creeks from their primary values of the original irrigation water in the main canal. The analysis was carried out by plotting the increment values of those water quality indices corresponding to the reused water that was stated in term of content ratio of total return flow (CTR). The value of CTR was defined as the ratio of total return flow to the total amount of water il a creek network. The results show that in fine days, $\triangle \mathrm{COD}$ and $\triangle \mathrm{EC}$ perform the same tendency of the relation to return flow, the value increases in line to raise in $C T R$. In rainy days, the increase of CTR will also increase $\triangle C O D$ and $\triangle E C$. But if CTR over $70 \%$, the change value of both water quality indices tend to decrease. For $\Delta \mathrm{T}-\mathrm{N}$, the plotted data are very scattered and the value fluctuates negatively and positively showing the purification process and the polluting action occur in paddy ficlds. Among the considered water quality parameters, it can be observed that the most severe index is COD, which recommends the value of CTK should not be higher than $55 \%$.
\end{abstract}

Key words : Reused water, Content ratio of irrigation return flow, Water quality

\section{INTRODUCTION}

Water quality is an important factor affecting the yields of water allocation and drainage control in an irrigation system. If water reuse exists, it needs much more to have a care on the irrigation water quality, because returned water may have severe impact on some water quality indices related to the existing crops.

This paper presents results of a study on such phenomenon for analyzing the relationship between the irrigation return flow and water quality changing. The goal of the study is to obtain the valuable evaluation on the characteristics of the water quality changing due to the operation of reused water irrigation system in the considered area. Performance of the water quality changing needs to be clarified by considering not only the existence of reused water, but also other related factors such as rainfall, fertilizer application and the growing stages of paddy plant.

\section{DESCRIPTION OF THE SURVEYED AREA}

\section{Geography and Climate}

The study was carried out as a case study at a low-lying paddy area in the Oide district, being a part of the Kase River Irrigation System. The surveyed area is located in 
the low-lying Saga plain facing the Ariake bay on the island of Kyushu, southwest Japan. Geographically, the area is very flat and just alluvial. The district is an artificially reclaimed area that is suitablc for agricultural fields. The climate in this region is mild; with the annual rainfall is around $1,800 \mathrm{~mm}$. In paddy planting period, the average daily temperature is $23.7^{\circ} \mathrm{C}$, while during non-paddy season it drops to $11.6^{\circ} \mathrm{C}$. As these conditions, the district is very suitable for paddy cultivation in summer season and it is called one of foremost granaries in Japan.

\section{Water Resources System and Layout of the Irrigation System}

Fig. 1 depicts the general scheme of the water resources system. The main resource is water storage in the Hokuzan reservoir with release and lateral inflow from the river basin being controlled by a regulating dam. Irrigation water for the Kase River Irrigation System, including water supply for the Oide District is taken from the Kawakami diversion, which flows to the delivery gates to each block of the creek network throughout the main canal system. A particular subject is the water operation in a creek-fields system as described in the following section.

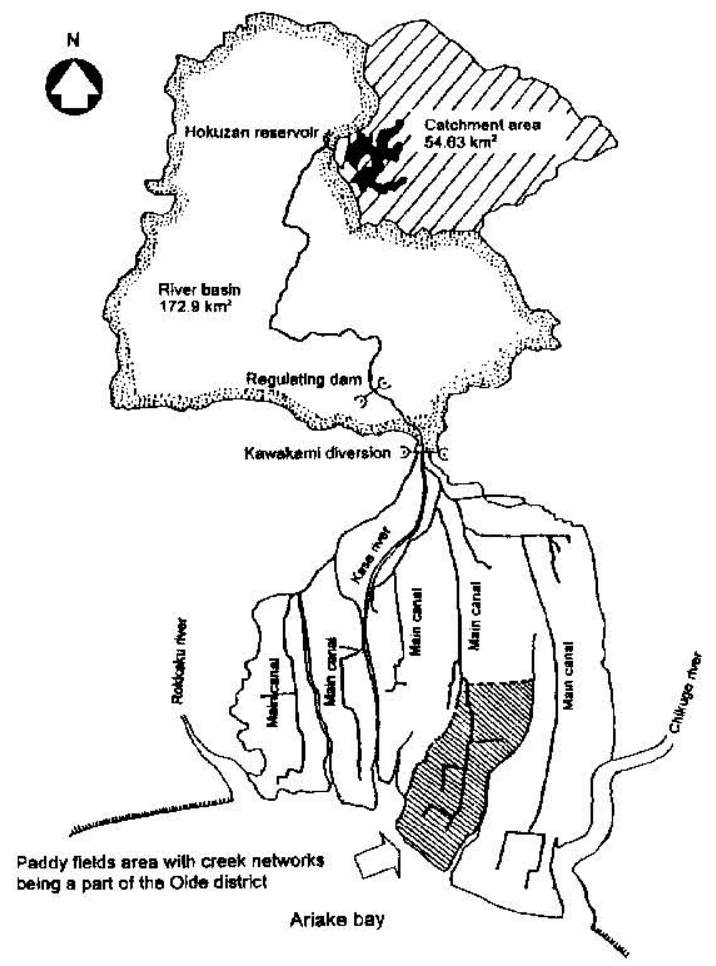

Fig. 1. Scheme of the water resources system

The Oide district comprises of eleven blocks of low-lying paddy area with creek networks as illustrated in Fig. 2. The considered area is the lower part of left side of the 
main canal which consists of five blocks namely $\mathbf{C}, \mathbf{D}, \mathbf{E}, \mathbf{F}$ and $\mathbf{G}$, from upstream side to downstream side respectively (Fig. 2.a).

The creeks were originally waterways in the swamp that performed canal networks inside the block area after reclamation. As shown in Fig. 2.b, a creck-fields system is characterized by the existence of water circulation between creek and the cultivated area in which surface runoff, seepage runoff and over supplied water of irrigated fields return again into creek networks. In this concern, a particular mention is the reuse mechanism of irrigation return flow, which intensively occurs in paddy fields and greenhouse.

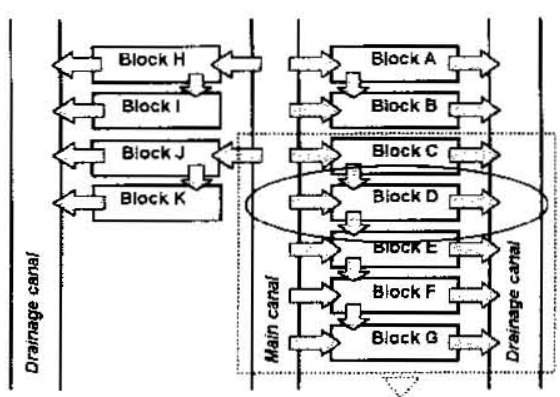

(a) Layout of the irrigation system

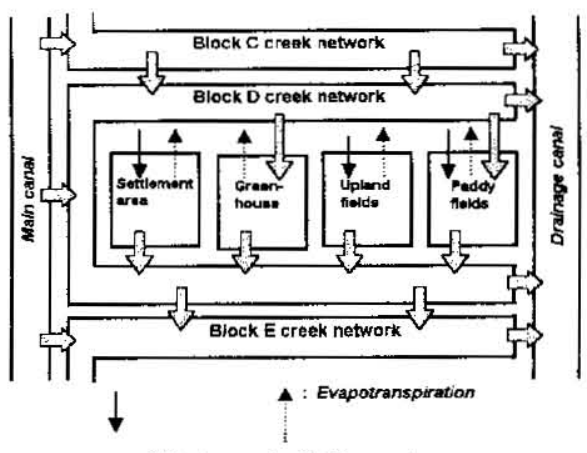

(b) A creek-fields system

Fig. 2. Schematic representation of the irrigation system layout

The operation of irrigation water is conducted by temporarily storing water in creek networks. The water level in creek is always lower than the irrigated fields. Therefore, a pumping system of irrigation water is usually applied. From Fig. 2.b it can be seen that circulation of the water reuse is performed not only within the creek-fields system of each block, but also among the blocks in which runoff from the upper block flows as irrigation water supply to the lower block of creek networks. Therefore, runoff from a concerning block to its lower area is an important data for analyzing the reuse mechanism of irrigation return flow.

\section{PROCEDURE FOR ANALYSIS}

There werc threc main activities of analysis have been carried out as shown in Fig. $\mathbf{3}$. First is water balance analysis using an appropriate complex Tank model (Jayadi, Fukuda and Kuroda, 1998) for simulating the cyclic water in the irrigated area. The main purpose of using the model is to find out the acceptable values of surface and sub surface runoff that flow into creek storage as return flow components. For each block of irrigated area the model consists of six sub Tank models that applicable for paddy fields, upland fields, greenhouse, settlement area, main canal and creek.

Second is simulation of return flow content ratio using a conceptual model based on the simple water balance approach (Jayadi, Fukuda and Kuroda, 1998). The calculated components of returned water and the simulated water depths in creeks were used to 
simulate the daily content ratio of return flow as explained in the next chapter.

The last step is observation of the impact of the water reuse on the water quality using the simulation output of the daily content ratio of return flow and the measured water quality indices. Field measurements were carried out in the regulating reservoir, the main canal and creeks. Measuring items were air tcmperature (T), dissolved oxygen (DO), $\mathrm{pH}$, suspended solids (SS), chemical oxygen demand (COD), electric conductivity (EC), total nitrogen ( $\mathrm{T}-\mathrm{N}$ ) and total phosphate (T-P). As paddy rice is the main crop, the analysis was focused on the increment values of $\mathrm{COD}, \mathrm{EC}$ and $\mathrm{T}-\mathrm{N}$ at arbitrary points in the creeks from their primary values of the original irrigation water in the main canal. These increment values were defined as $\Delta \mathrm{COD}, \Delta \mathrm{EC}$ and $\Delta \mathrm{T}-\mathrm{N}$.

For the analysis, hydrological data, meteorological data and measuring water qualities at some representative points were exploited for both model calibration and water quality assessment. Those kinds of data were collected by periodically field surveys and laboratory works.

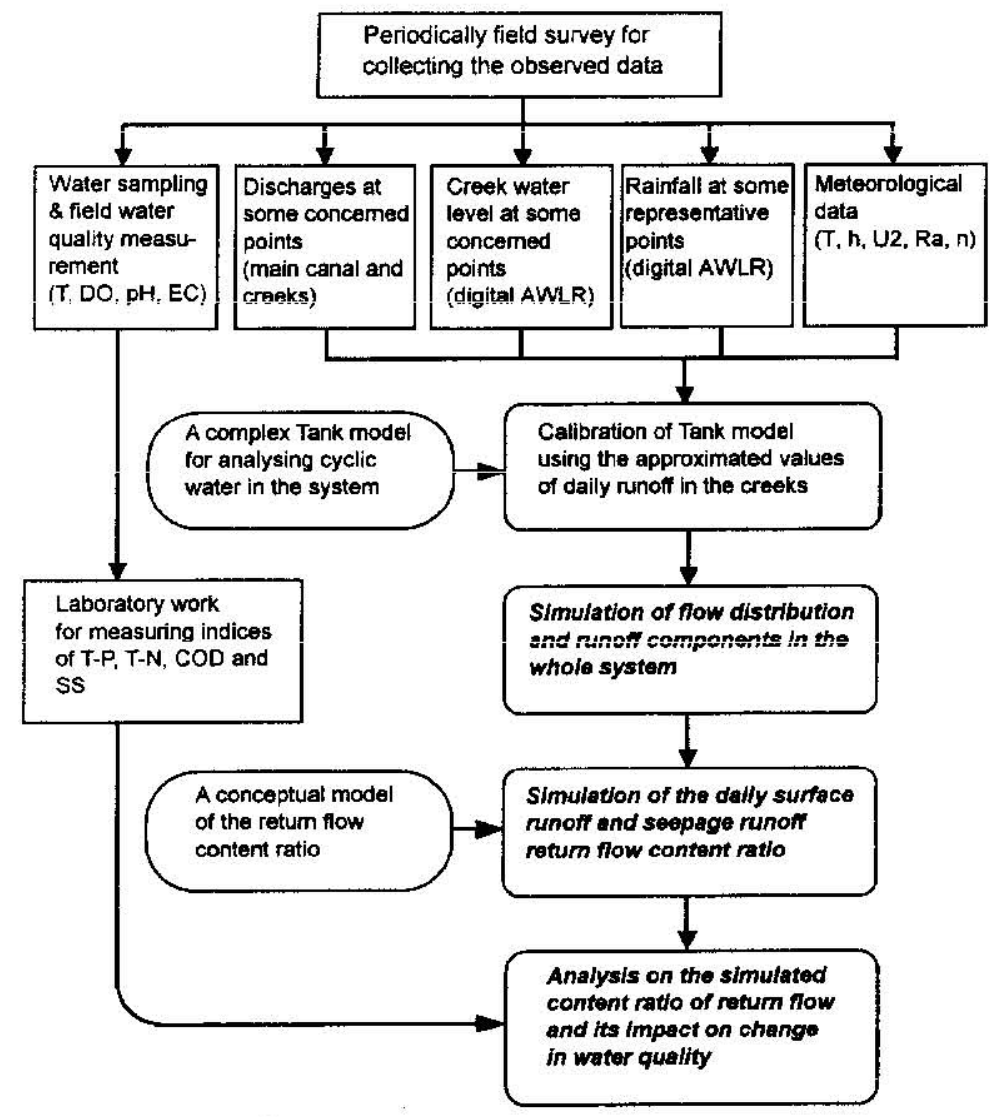

Fig. 3. Diagram of procedure for analysis 


\section{A CONCEPTUAL MODEL OF RETURN FLOW CONTENT RATIO}

As return flow components have been calculated by the complex Tank model, a simple logical trcatment can easily be applied to develop a conceptual model of return flow content ratio as represented in Fig. 4. The calculated components of returned water and the simulated water depths in creeks were used to simulate the daily content ratio of return flow.

The returned water was divided into two components of return flow, stated as surface runoff return flow and seepage runoff return flow. The remaining component of flow in creek was treated as original irrigation water. The content ratio of each component of return flow was calculated with respect to the total amount of stored water in creek. Therefore, the total value of these content ratios is equal to one. In this study we defined the ratio of total amount of surface runoff and seepage runoff return flow to the total amount of water stored in each creek network as the content ratio of total return flow (CTR).

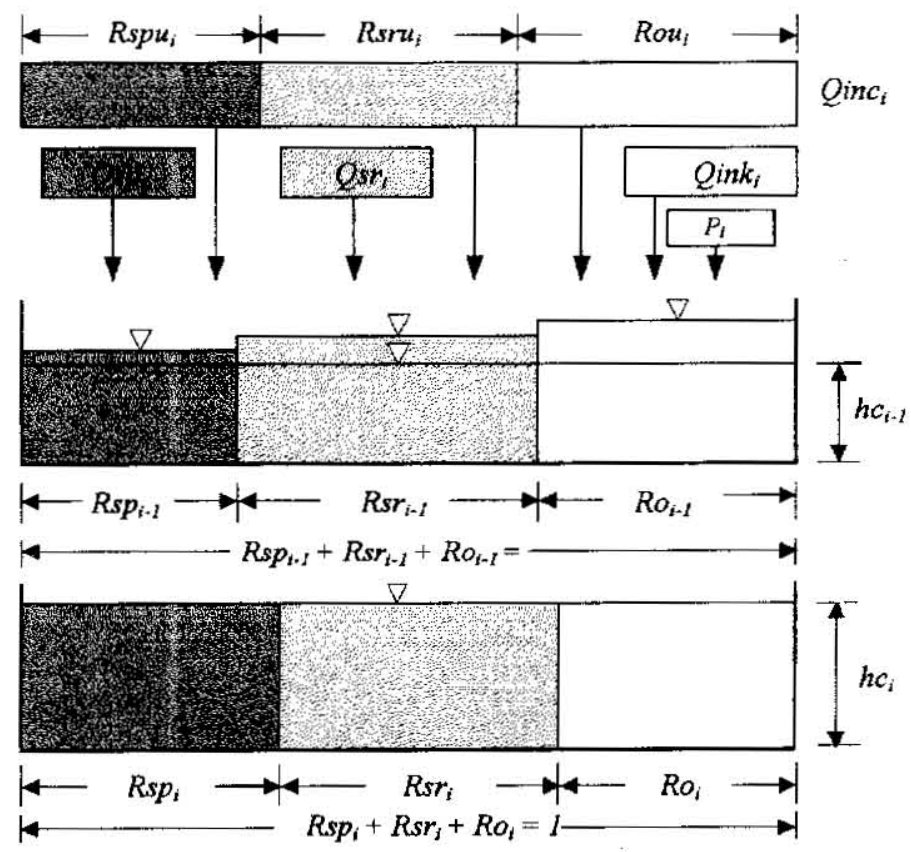

Fig. 4. A Conceptual model of return flow content ratio

The results are expressed in equations (1), (2) and (3).

$$
\begin{aligned}
& R s p_{i}=\frac{h c_{i}: R s p_{i-1} \cdot 10 A c_{i}+Q s p_{i}+Q i n c_{i} \cdot R s p u_{i}}{h c_{i} \cdot 10 A c_{i}+Q o u t_{i}} \\
& R s r_{i}=\frac{h c_{i-1} \cdot R s r_{i-1} \cdot 10 A c_{i}+Q s r_{i}+Q i n c_{i} \cdot R s r u_{i}}{h c_{i} \cdot 10 A c_{i}+\text { Quut }_{i}} \\
& R O_{i}=1.0-R s p_{i}-R s r_{i}
\end{aligned}
$$


$R s p, R s r$ are the content ratio of seepage runoff and surface runoff return flow, respectively. Rspu and Rsru are expression of the content ratios, which are applied for flow from the upper block. Ro is the content ratio of original irrigation water. Qsp and Qsr are discharge of seepage runoff and surface runoff return flow, respectively. Qout is the water flows to the outside of the concerning block. $A c$ is the average area of creek storage at water surface and $h c$ is creek water depth. Qinc is water flow from the upper block of creek network. Subscript $i$ means the day of concerning calculation period. The $C T R$ is equal to $R s p+R s r$.

\section{RESULTS AND DISCUSSION}

\section{The Daily Content Ratio of Return Flow}

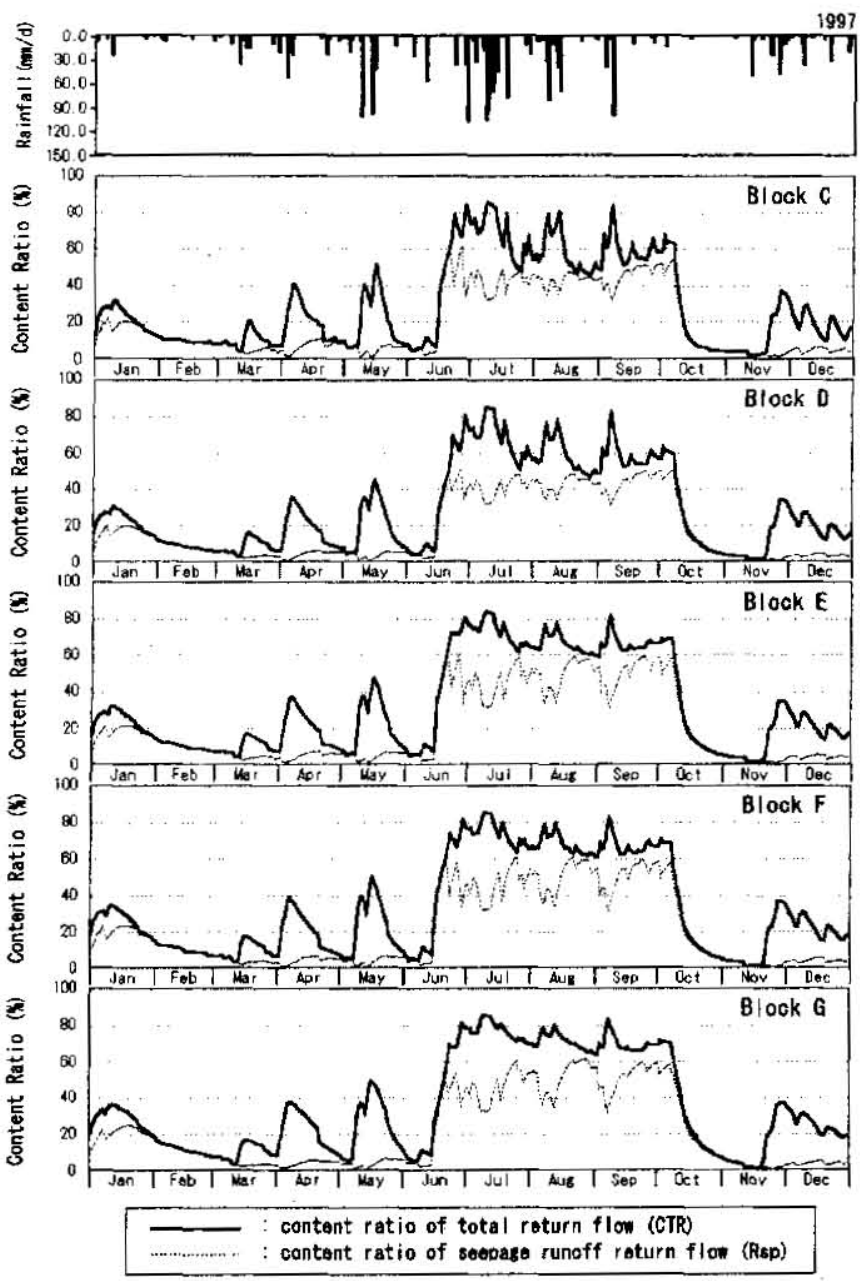

Fig. 5. The daily content ratio of return flow, 1997 
Fig. 5 shows example of the simulated daily content ratio of return flow in the year of 1997. From the figure it is seen that during paddy season, both the content ratio of seepage runoff $(R s p)$ and the content ratio of total return flow $(C T R)$ were higher than those in non-paddy season. Surprisingly, CTR of each block in a rainy day could reach a value more than $80 \%$. In fine days, the $C T R$ decreased with the minimum values was about $50 \%$ in block $\mathbf{C}$ and $\mathbf{D}, 60 \%$ in block $\mathbf{E}$ and $\mathbf{F}$, and $65 \%$ in block $\mathbf{G}$.

It can also be seen that in a fine day $R s p$ is the dominant part of the return flow. But, a certain amount of surface runoff appears in a rainy day. This feature clearly indicates that paddy fields release the seepage runoff return flow intensively due to the high rate of percolation. As farmers are usually keep the depth of water pond within the required amount of water, such phenomenon was realized by the analysis.

In the period of non-paddy season, paddy fields change to be the cultivated areas for upland crops such as wheat, bariey and onion, which require a limited supply of irrigation water, so that the runoff response depends on the rainfall. The figure also clearly expresses such hydrological process in which the surface runoff return flow fits well to the rainfall.

\section{Alteration of the Measured Water Quality Indices}

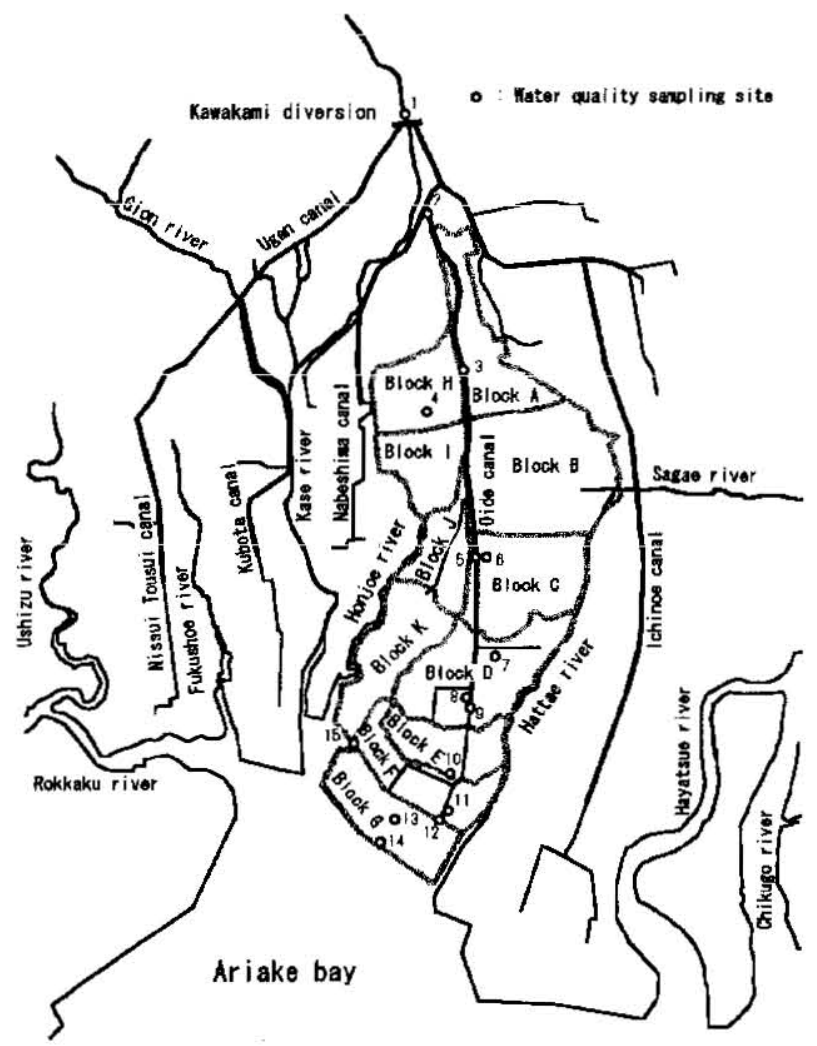

Fig. 6. Locations of water quality measurements 
Field works and laboratory measurements of water quality were periodically carried out for both during irrigation and non-irrigation periods (paddy and non-paddy seasons) of 1997. Measurement points are shown in Fig. 6, i.e., at main canal and creeks. Conceming the study is focused in paddy rice cultivation; in this study we selected 6 locations of sampling sites in which the observed data are representative of water quality characteristics of the study area. Measurement point 2 (L2) located at the upstream reach of the main canal, while the others distributed along creek networks from the most upper block to the lowest block. Locations 6 and 8 are located at Honjo and Tanaka,
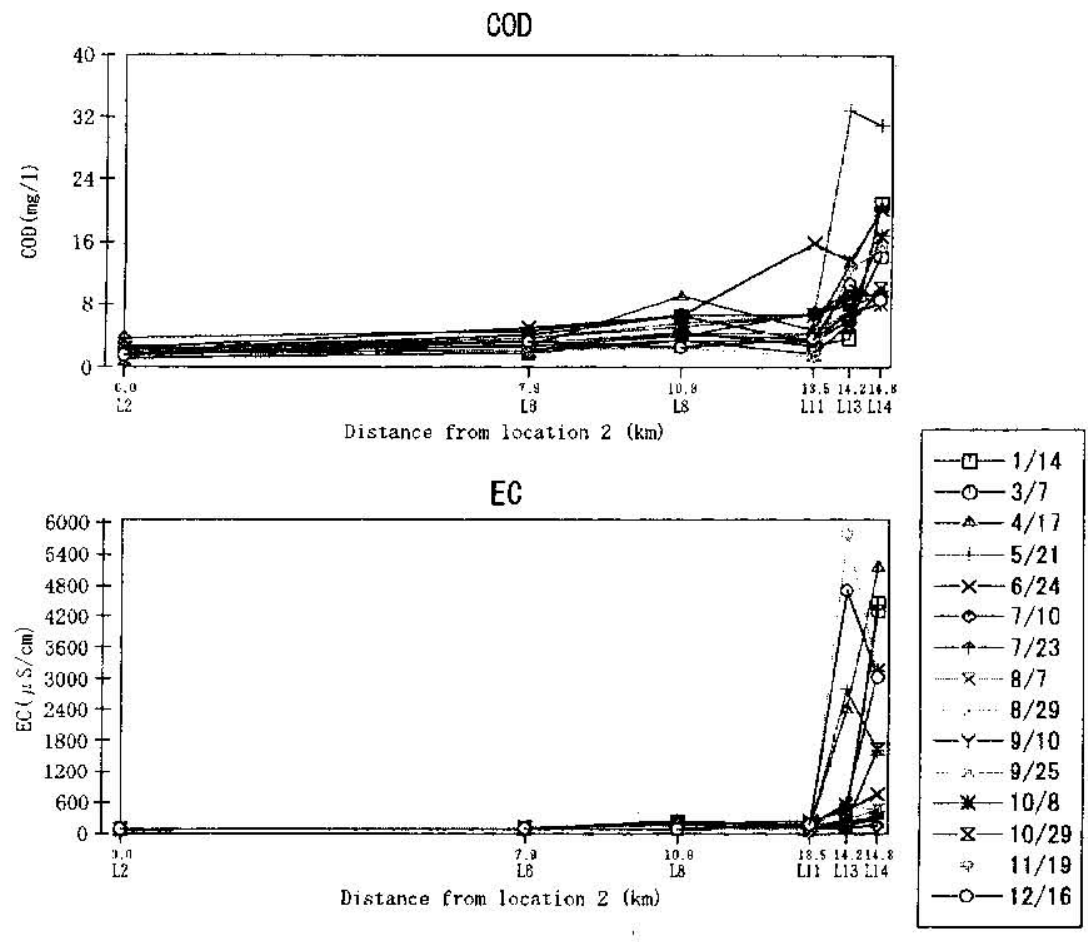

I-N

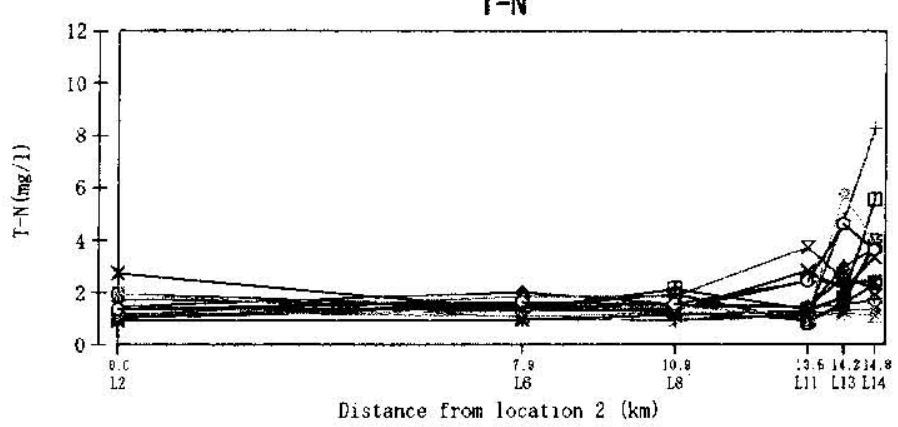

Fig. 7. The measured water quality indices at the sampling sites, 1997 
respectively. Measurement points 11 (Daiju 1) is situated in the downstream reach of creek network, while points 13 (Daiju2) and 14 (Daiju3) are located at the lowest block of paddy fields area of the Oide district.

Fig. 7 shows graphs of the measured water quality versus sampling site for the indices of chemical oxygen demand (COD), electric conductivity (EC) and total nitrogen $(\mathrm{T}-\mathrm{N})$. According to the water quality restriction index for paddy rice cultivation in Japan (Tabuchi, et al, 1998), several points were emphasized. From the figure can be observed that the value of COD toward downstream tended to increase and so its fluctuation as well as the variation. In Honjo and Tanaka, the fluctuation of COD values was relatively small. But at the downstream area of Daiju $(\mathrm{L11}, \mathrm{L13}$, and L14) shown the great increase of COD that extremely over the limit, particularly at the Daiju2 and Daiju3.

The value of EC towards the downstream tended to increase exponentially. From the upstream reach point up to Tanaka the graph shows insignificant variation and fluctuation of $\mathrm{EC}$ values, but at its lower region the valucs increase drastically that could over $5,000 \mu \mathrm{S} / \mathrm{cm}$. The graph also shows the characteristics of $\mathrm{T}-\mathrm{N}$ index that in the upstream and downstream part performed highly values as well as its variation and fluctuation. The fluctuation of ' $\mathrm{T}-\mathrm{N}$ value seems increase drastically, particularly at the downstream points. Similar to the appearance of COD values measured at crecks, the low values of $\mathrm{T}-\mathrm{N}$ were found only at Tanaka and Honjo.

Generally speaking, it can be said that the values of water quality index observed at the downstream area are commonly high. It caused by the relatively unmovable water that leads to decrease in quality. In addition is polluting action due to the reuse cycles of irrigation water, in which the polluted return flow by some chemical substances is accumulated in creek storage. It indicates that the reused water irrigation system may cause severe impact on water quality.

\section{Assessments of the Relationships Between Return Flow and Water Quality Changing}

To make clear the influence of the reused water on the irrigation water quality, the measured water quality indices ( $\Delta \mathrm{CON}$ ), $\Delta \mathrm{EC}$ and $\Delta \mathrm{T}-\mathrm{N}$ ) were plotted corresponding to the content ratio of total return flow (CTR). Fig. 8 shows graphs of the observed data of the water quality changing corresponding to the calculated return flow content ratio for the paddy season of 1996-1997.

In general, it can be seen that $\triangle$ COD and $\triangle \mathrm{EC}$ show the similar tendency of relationship to $C T R$. Both of the measured water quality indices tend to increase in accordance with increase in $C T R$ value. In the case of $\Delta \mathrm{T}-\mathrm{N}$, its relation to $C T R$ does not show the distinct trend. The plotted data are very scattered, particularly during fine days. $\Delta \mathrm{T}-\mathrm{N}$ fluctuates negatively and positively from -1.4 to $2.5 \mathrm{mg} / \mathrm{l}$, which shows that paddy fields perform purification and pollution processes of nitrogen.

In evaluating the influence of the water reuse on the irrigation water quality, we used the restriction indices for paddy rice cultivation that applicable in Japan. These restricted values are $6.0 \mathrm{mg} / \mathrm{l}$ for $\mathrm{COD}, 300 \mu \mathrm{S} / \mathrm{cm}$ for $\mathrm{EC}$ and $3 \mathrm{mg} / \mathrm{l}$ for T-N (Tabuchi et al., 1998). The primary values of COD, EC and T-N are around $2-3 \mathrm{mg} /, 60-90 \mu \mathrm{S} / \mathrm{cm}$ and $1-2 \mathrm{mg} / \mathrm{l}$, respectively. It means that the maximum acceptable values of $\Delta \mathrm{COD}, \Delta \mathrm{EC}$ and $\Delta \mathrm{T}-\mathrm{N}$ are around $3.0 \mathrm{mg} / 1,200 \mu \mathrm{S} / \mathrm{cm}$ and $1 \mathrm{mg} /$, respectively. From Fig. 8.a and $\mathbf{8 . b}$ it can be 


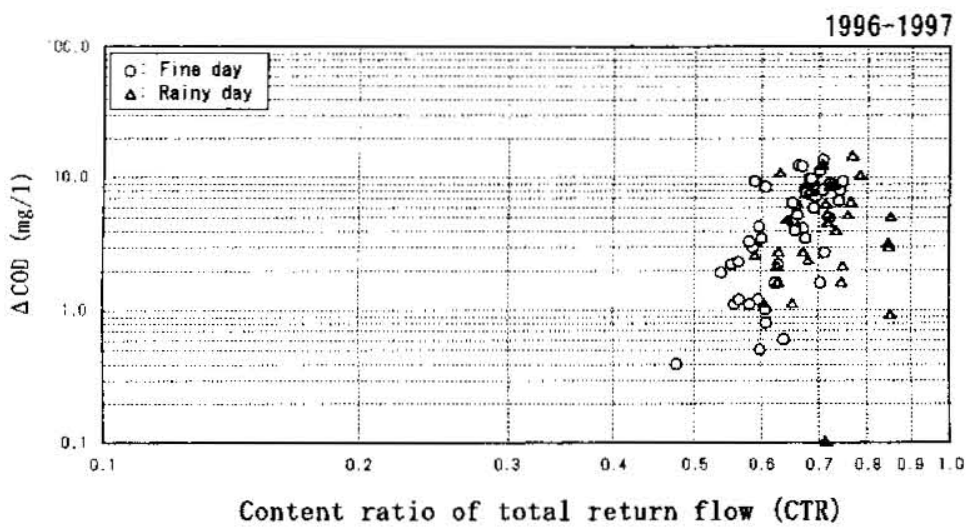

(a) $\triangle$ COD vs. CTR

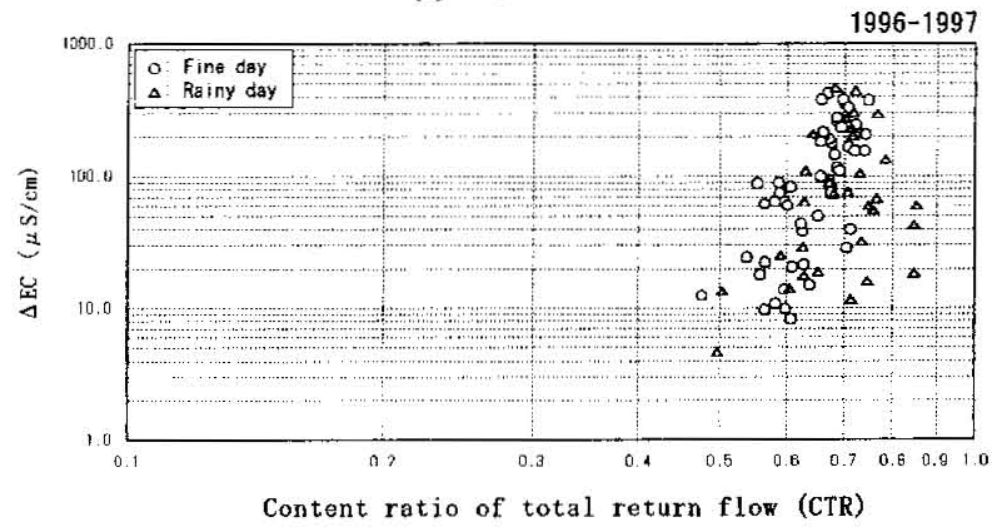

(b) $\triangle \mathrm{EC}$ vs. CTR

1996-1997

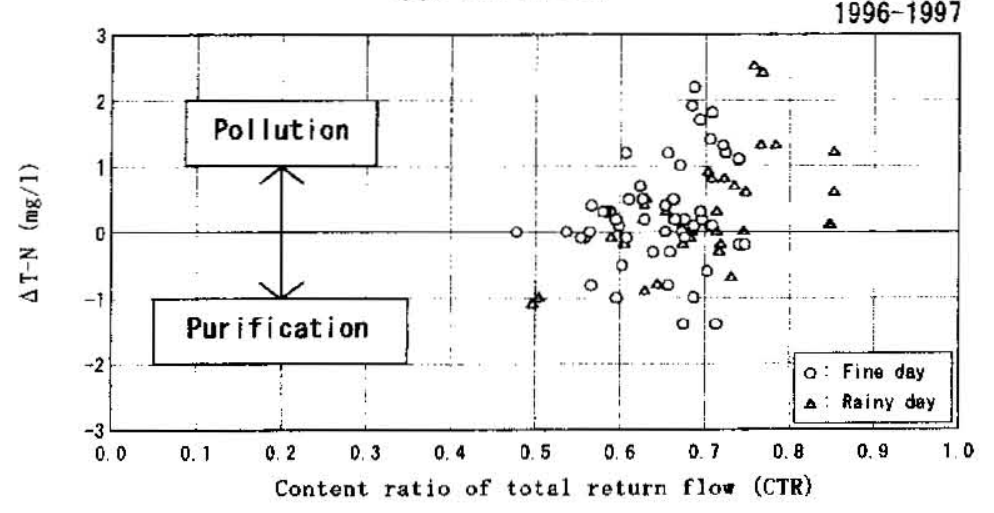

(c) $\triangle T-N$ vs. CTR

Fig. 8. The change of water quality versus $C T R$ for the whole days observation period, 1996-1997 
observed that the maximum values of CTR corresponding to $\triangle \mathrm{COD}$ and $\triangle \mathrm{EC}$ are around $55 \%$ and $60 \%$, respectively. It was found that the observed value of $\mathrm{T}-\mathrm{N}$ which higher than $3 \mathrm{mg} / \mathrm{l}$ was very rare (see Fig. 8.c). So it can be concluded that the most severe index is COD, which recommends the value of CTR should not be higher than $55 \%$.

To see more detail on such phenomena, it is necessary to observe the relationship of the two factors in fine days and in rainy days observation period separately. Fig. 9 can be used for obtaining a more clear assessment of characteristics of the water quality changing towards the reused water.

It seems that in usual fine days, $\triangle \mathrm{COD}$ and $\triangle \mathrm{EC}$ have the same tendency of the relationship to the return flow. Fig. 9.a and $\mathbf{9 . b}$ clearly show that the change value of the

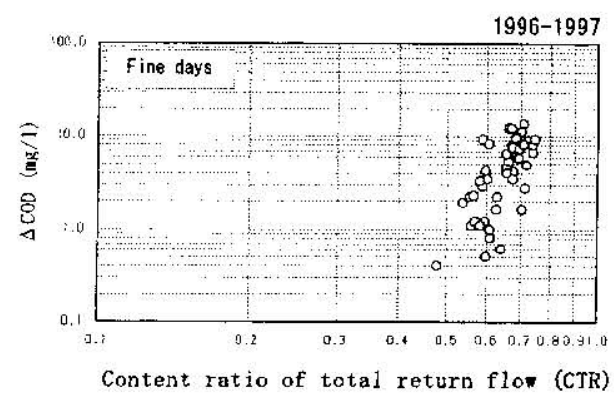

(a) $\triangle$ COD vs. CTR in fine days

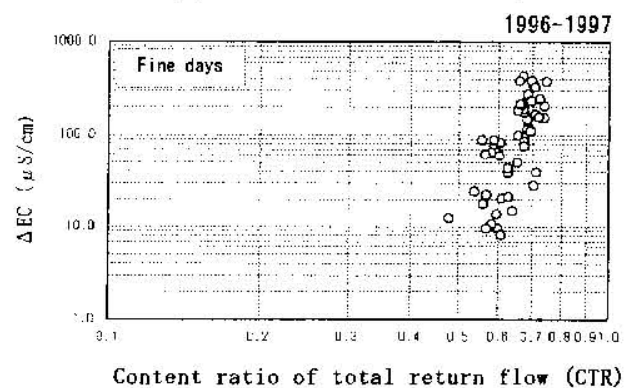

(b) $\triangle \mathrm{EC}$ vs. $C T R$ in fine days

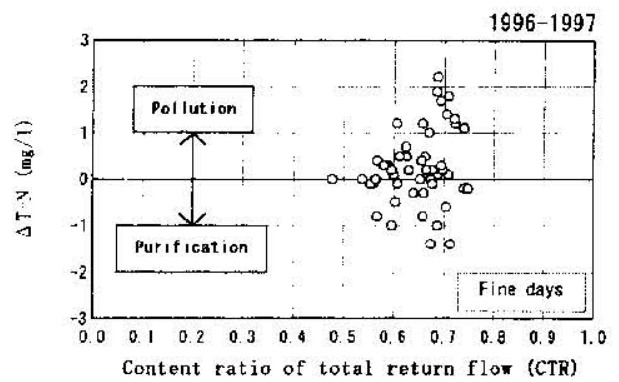

(c) $\triangle \mathrm{T}-\mathrm{N}$ vs. $C T R$ in fine days

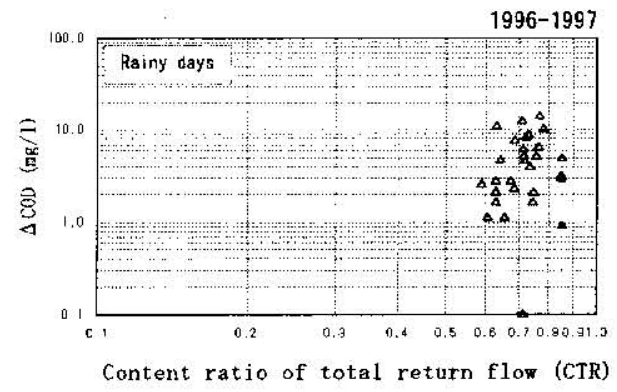

(d) $\triangle$ COD vs. CTR in rainy days

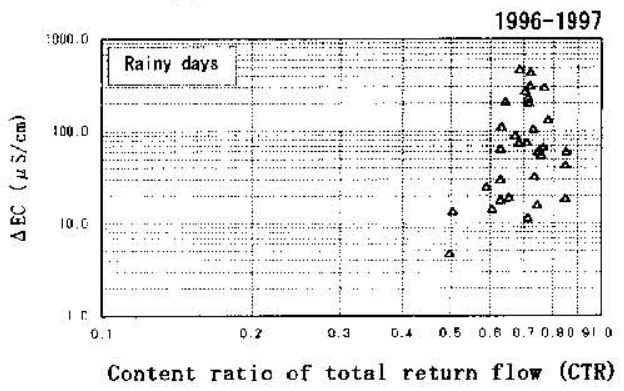

(c) $\triangle \mathrm{EC}$ vs. CTR in rainy days

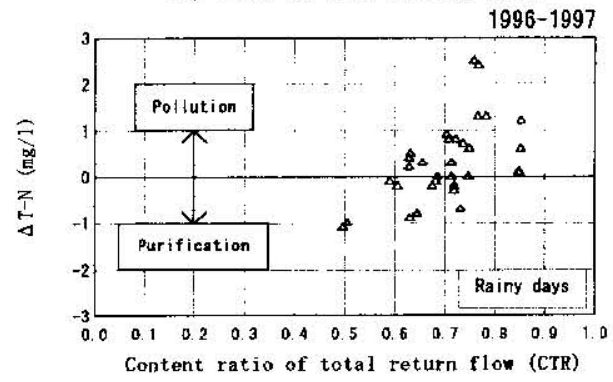

(f) $\triangle \mathrm{T}-\mathrm{N}$ vs. CTR in rainy days

Fig. 9. The change of water quality versus $C T R$ in fine days and in rainy days observation period, 1996-1997 
two water quality indices increase in accordance with the increase of CTR. In this period, the seepage runoff return flow is much higher than the surface runoff return flow which shows that unclean water of seepage runoff return flow originates from paddy plots and settlement areas flow out intensively, but the amount of surface runoff return flow is very small. Consequently, stored water in the creek performs pollution action stronger than the dilution process.

Fig. 9.c describes pattern of $\Delta \mathrm{T}-\mathrm{N}$ in usual fine days. The fluctuation of total nitrogen in paddy plots is highly affected by the capability of paddy plant in consuming nitrogen. The negative values of $\Delta \mathrm{T}-\mathrm{N}$ appear in the end of June and the middle until the end of August, in which the nitrogen absorption reaches the maximum rate. Although the end of August is the fertilizing period, but if there is no rainfall, the effect of nitrogen absorption is higher than the influence of the supply of nitrogen from the fertilizer substance. For the other periods of fertilizer application (July and the beginning of August), $\Delta \mathrm{T}-\mathrm{N}$ have positive values due to the low rate nitrogen absorption by paddy plant and the supply of nitrogen contained in fertilizer matter.

As shown in Fig. 9.d and 9.e, during the rainy period both $\Delta$ COD and $\triangle$ EC perform the double trends of relationship to CTR. The increase in CTR up to $70 \%$ causes the value of $\triangle \mathrm{COD}$ and $\triangle \mathrm{EC}$ rise, but when the value of $C T R$ over $70 \%$, the change values of both water quality indices tend to decrease. This feature is verified by the identified characteristics of the daily return flow obtained in the previous study (Jayadi, Fukuda and Kuroda, 1998) showing when the abundant rainfall occurs, CTR value will be higher than $70 \%$ due to the large value of surface runoff return flow. In this condition, the influence of dilution is more dominant than the pollution effect, so that the concentrations of COD contained in creek water tend to decrease. Moreover, when there is a heavy rainfall occur, salinity of stored water in the creek will decline due to the decrease in concentration of salty substances contained in creek water. It causes the value of EC to decrease. This phenomenon conforms to the observed data showing that the low values of $\triangle C O D$ and $\triangle E C$ occur in heavy rainy days.

Fig. 9.f shows that in rainy days, pattern of the change in $\Delta \mathrm{T}-\mathrm{N}$ with respect to CTR seems to be a linear relationship. In this period, process of nitrogen absorption in paddy fields also contributes significantly in determining the concentration of total nitrogen in the creek water. The high positive values of $\Delta \mathrm{T}-\mathrm{N}$ occurred in the beginning of July and August, because there was much rainfall just after fertilizer application. The nitrogen contained in water pond of paddy plots was transported to the creek storage by the surface runoff return flow. On the contrary, in the end of August in which the nitrogen absorption rate was high and there was not so much rain that resulted in a small amount of surface runoff return flow only. Because of the stronger effect of the high absorption rate than the influence of polluting action, the values of $\Delta \mathrm{T}-\mathrm{N}$ were negative.

\section{CONCLUSIONS}

The study so far presents the results of evaluation on the reused water effect to the water quality. Even though with the existence of the creek networks inside of the irrigation area the water reuse can be implemented for conserving the water resources, but it was proven that this method could give negative effect on the irrigation water quality. 
The negative effect of the reused water to the irrigation water quality is shown by the appearance of unsuitable value of water quality indices, COD, EC and T-N that exceeded the restricted value for paddy plant. Among these parameters, the most severe index is COD, which recommends the value of CTR should not be higher than $55 \%$.

Further study is necessary to find the valid quantitative formulation of such relationships, such that the important factors affecting the irrigation water quality can be incorporated for establishing a more reliable operating rule of water allocation and drainage control in the considered irrigation system.

\section{REFERENCES}

R. Jayadi, T. Fukuda and M. Kuroda 1998 Reuse Mechanism of Irrigation Return Flow and Its Impact on Water Quality, Proceeding of the $11^{*}$ Congress of APD-IAHR, vol. 1, pp. 221-230.

T. Tabuchi, S. Anraku, H. Nakasone and Y. Yuyama 1998 Water Quality Environment, The Japanese Society of IDRE, pp. 21-23 (in Japanese). 